\title{
Article
}

\section{Effects of a 4-week intervention using semi-custom insoles on perceived pain and patellofemoral loading in targeted subgroups of recreational runners with patellofemoral pain}

Sinclair, Jonathan Kenneth, Janssen, Jessica, Richards, James, Butters, Bobbie, Taylor, Paul John and Hobbs, Sarah Jane

Available at http://clok.uclan.ac.uk/23795/

Sinclair, Jonathan Kenneth ORCID: 0000-0002-2231-3732, Janssen, Jessica ORCID: 0000-0002-5961-2736, Richards, James ORCID: 0000-0002-40043115, Butters, Bobbie, Taylor, Paul John ORCID: 0000-0002-9999-8397 and Hobbs, Sarah Jane ORCID: 0000-0002-1552-8647 (2018) Effects of a 4-week intervention using semi-custom insoles on perceived pain and patellofemoral loading in targeted subgroups of recreational runners with patellofemoral pain. Physical Therapy in Sport, 34 . pp. 21-27. ISSN 1466-853X

It is advisable to refer to the publisher's version if you intend to cite from the work. http://dx.doi.org/10.1016/j.ptsp.2018.08.006

For more information about UCLan's research in this area go to http://www.uclan.ac.uk/researchgroups/ and search for <name of research Group>.

For information about Research generally at UCLan please go to http://www.uclan.ac.uk/research/

All outputs in CLoK are protected by Intellectual Property Rights law, including Copyright law. Copyright, IPR and Moral Rights for the works on this site are retained by the individual authors and/or other copyright owners. Terms and conditions for use of this material are defined in the policies page. 


\section{$4 \quad$ Abstract}

5 OBJECTIVE: Explore the effects of a 4-week intervention using semi-custom insoles in

6 recreational runners with patellofemoral pain.

7 DESIGN: Mixed methods

\section{patellofemoral pain.}

PARTICIPANTS: Seventeen (10 males and 7 females) recreational runners.

SETTING: Laboratory

OUTCOME MEASUREMENTS: Participants were separated into specific subgroups, then provided with a pair of semi-custom insoles, for a period of 4-weeks. Lower extremity kinetics/kinematics during running at $4.0 \mathrm{~m} / \mathrm{s}$ were obtained. In addition, knee pain was examined using the Knee injury and Osteoarthritis Outcome Score-Patellofemoral scale (KOOS-PF). Data were collected before and after wearing the insoles for 4-weeks.

RESULTS: Significant improvements were shown for KOOS-PF in both subgroups (strong: $($ pre $)=63.84 \&$ (post) $=71.49$ and weak and tight: (pre) $=53.03 \&$ (post)=72.73), although only improvements in the weak and tight group exceeded the minimum clinically important difference (MCID). In addition, significant reductions in peak patellofemoral stress were shown in both subgroups (strong: (pre)=6.82 \& (post)=6.39KPa/BW and weak and tight: (pre)=7.66 \& (post) $=6.28 \mathrm{KPa} / \mathrm{BW})$, although only reductions in the weak and tight group exceeded the MCID.

CONCLUSIONS: Semi-custom insoles may be a mechanism to reduce patellofemoral pain symptoms in recreational runners from the weak and tight subgroup. It is proposed that this improvement was mediated through reductions in patellofemoral loading in this subgroup. 
Keywords: patellofemoral pain; patellofemoral loading; subgrouping; insoles

27

\section{Introduction}

Recreational running is an extremely popular physical and leisure modality, known to provide a plethora of physiological and psychological benefits (Lee et al., 2014). Over 2million people in the UK utilize running as a regular mode of exercise (Sport England, 2014). However, despite the clear physical benefits mediated by running, it is also known to be associated with a high incidence of chronic pathologies. Over the course of one-year as many as $80 \%$ of runners will experience an overuse injury as a consequence of their training (Van Gent et al., 2007).

Patellofemoral pain is the most common chronic pathology in runners (Taunton et al., 2002), which typically manifests as retropatellar or diffuse peripatellar pain, aggravated by activities such as running that frequently load the joint (Crossley et al., 2016). Elevated patellofemoral joint stress, which is a reflection of the patellofemoral joint reaction force divided by the patellofemoral contact area, is commonly accepted as a key aetiological factor in the development of patellofemoral pain syndrome (Farrokhi et al., 2011).

The long term prognosis for those who present with patellofemoral pain is poor, with between 71-91\% all patients experiencing ongoing symptoms up to 20 years following diagnosis (Nimon et al., 1998). Female recreational runners are 2-3 times more likely to suffer from patellofemoral pain in comparison to males (Robinson \& Nee, 2007), owing to increased dynamic knee abduction (Malinzak et al., 2001; Ford et al., 2003; Sakaguchi et al., 2014), hip internal rotation (Lephart et al., 2002; Decker et al., 2003), hip adduction 
(Malinzak et al., 2001; Lephart et al., 2002), hip abductor (Sugimoto et al., 2014) and

quadriceps strength (Lephart et al., 2002). Importantly, those who experience patellofemoral

symptoms may later present with radiographic evidence of osteoarthritis at this joint (Thomas

et al., 2010). Pain symptoms force many runners to reduce or even end their participation in

running activities (Blond \& Hansen, 1998), and many individuals with patellofemoral pain

develop associated psychological disorders including mental distress and self-perceived

health (Jensen et al., 2005); pain-related fear, low self-efficacy and fear of the future (Smith

et al., 2018); kinesiophobia, depression and catastrophizing (Maclachlan et al., 2018).

60

As a consequence of the high incidence of patellofemoral pain, a significant range of conservative treatment modalities have been explored in biomechanical and clinical literature; including exercise therapy, taping, bracing, insoles, soft tissue manipulation and acupuncture (Smith et al., 2017). Pain is the key clinical symptom associated with patellofemoral syndrome, thus the attenuation of pain through conservative modalities is of considerable interest to both clinicians and researchers alike. Insoles utilized by runners typically feature a contoured medial arch profile, and offer a mechanism by which lower extremity joint loading can be altered.

The acute effects of foot insoles on the kinetics and kinematics of running are well documented, but there is currently a paucity of research investigating biomechanical adaptations over time, or the effectiveness of insoles for the treatment of patellofemoral pain symptoms. Two studies are however of note. Collins et al., (2008) examined the efficacy of foot orthoses, flat inserts and multimodal physiotherapy in patients with clinically diagnosed patellofemoral pain. Their results showed that all three treatments mediated significant and 
76 clinically meaningful improvements in pain symptoms. Eng and Pierrynowski, (1993) assigned a group of adolescent female patients with patellofemoral pain to either: a control who undertook an exercise program, or a treatment group who were provided with soft insoles in addition to participating in the exercise program. Their findings showed that both the treatment and control groups exhibited significant reductions in pain, but that improvements in the treatment group were significantly greater than those in the control group. Both studies indicate that soft insoles may be beneficial in the treatment of patellofemoral pain symptoms for patients, but whether these findings also apply to recreational runners with patellofemoral pain symptoms is unknown.

Different factors may predispose recreational runners compared to patients to the development and therefore treatment of patellofemoral pain symptoms, due to their physiological differences. Selfe et al., (2016) recently identified three subgroups of patients with patellofemoral pain ('strong', 'weak and tight' and 'weak and pronated foot') using six low cost, simple clinical assessment tests that can be applied in routine practice. This initial study suggested that developing a strategy to target specific interventions for each subgroup may ultimately lead to improved patient outcomes. The current study aimed to explore the effects of a 4-week intervention using semi-custom foot insoles on pain symptoms and patellofemoral loading in subgroups of recreational runners.

\section{Methods}

Participants

Seventeen participants (10 male and 7 female), volunteered to take part. Participants were invited to attend the laboratory if they suffered from self-reported knee pain exacerbated by their running training. Specific diagnosis of patellofemoral was made in accordance with the 
there was evidence of any other knee pathology or they had previously undergone surgery on

being caused by degenerative joint disease. Written informed consent was provided in

accordance with the declaration of Helsinki. The procedure was approved by the Universities

Science, Technology, Engineering, Medicine and Health ethics committee, with the reference STEMH 424.

Procedure

111 Participants attended the laboratory on two occasions. On the first occasion the participants were assessed using the six clinical tests described by Selfe et al. (2016) on their affected limb only. These assessments involved two muscle strength tests (quadriceps and hip abductors), two muscle length tests (m. gastrocnemius and $\mathrm{m}$. rectus femoris), one patellar mobility test, and one foot posture index test (Redmond et al., 2006). Based on this information participants were sub-grouped in accordance with Selfe et al. (2016) which revealed that participants belonged to either the 'strong' $(\mathrm{N}=11)$ or weak and tight $(\mathrm{N}=6)$ groups (Table 1). All other tests were completed on both occasions.

@@@TABLE 1 NEARHERE@@@

Clinical tests

Initially participants completed the Knee injury and Osteoarthritis Outcome ScorePatellofemoral subscale (KOOS-PF) (Crossley et al., 2017) and Coop-Wonca questionnaires 
126 Biomechanical data was then collected from the participants during running trials in their 127 own footwear, as described below.

Intervention

130 Once the biomechanical and KOOS-PF data were obtained, participants were then provided with a pair of off-the-shelf insoles (Sole Control, Sole, Milton Keynes, UK) in their size. The insoles were made from ethylene-vinyl acetate and had a shore A 30 hardness rating. Because the participants from both subgroups did not exhibit an everted foot posture, the insoles did not feature any rearfoot posting. Participants were asked to wear the insoles for all of their running training for 4-weeks (Bolgla \& Boling, 2011). To mould the insoles they were placed into a pre-heated oven $\left(90^{\circ} \mathrm{C}\right)$ for a duration of two minutes. The heated insoles were then placed inside the participants shoes. Participants were asked to stand upright without moving for two minutes to allow the process of moulding the insoles to the longitudinal arch profile of each participant, in accordance with manufacturer instructions. Insoles were placed inside both shoes although only the pathological side was examined. Participants were instructed to maintain their habitual training regime. They recorded the number of completed kilometers during the 4-week period prior to the intervention and again during the 4-week intervention period. Following the 4-week intervention participants returned to the laboratory where the complete protocol was repeated whilst wearing their insoles.

\section{Biomechanical tests}

147 Participants ran at a velocity of $4.0 \mathrm{~m} / \mathrm{s} \pm 5 \%$, striking an embedded piezoelectric force platform (Kistler, Kistler Instruments Ltd., Alton, Hampshire; length, width, height $=0.6 \mathrm{x}$ $0.4 \times 0 \mathrm{~m}$ ) with their affected limb. The force platform sampled at $1000 \mathrm{~Hz}$. Running velocity was quantified using infrared timing gates, which were positioned $4 \mathrm{~m}$ apart. The stance 
phase of running was delineated as the duration over which $>20 \mathrm{~N}$ of vertical force was

152

153

154

155

156

157

158 applied to the force platform. A successful trial was defined as one within the specified velocity range, where the foot made full contact with the force platform and where no evidence of gait modifications due to the experimental conditions were evident.

Kinematics and ground reaction force (GRF) information were synchronously collected. Kinematic data were captured at $250 \mathrm{~Hz}$ via an eight camera motion analysis system (Qualisys Medical AB, Goteburg, Sweden). Dynamic calibration of the motion capture system was performed before each data collection session.

Lower extremity segments were modelled in 6 degrees of freedom using the calibrated anatomical systems technique (Cappozzo et al., 1995), using a marker configuration utilized previously to quantify the effects of orthoses patellofemoral joint kinetics (Sinclair, 2018). To define the anatomical frames of the pelvis, thigh, shank and foot retroreflective markers were positioned onto the iliac crest, anterior superior iliac spine (ASIS), and posterior super iliac spine (PSIS). In addition, further markers were placed unilaterally onto the medial and lateral malleoli, greater trochanter, medial and lateral femoral epicondyles, calcaneus, first metatarsal and fifth metatarsal heads of the affected limb. Foot markers were positioned onto the upper of the participants' shoes. Carbon-fiber tracking clusters comprising of four nonlinear retroreflective markers were positioned onto the thigh and shank segments. In addition to these the foot segments were tracked via the calcaneus, first metatarsal and fifth metatarsal, and the pelvic segment was tracked using the PSIS and ASIS markers. Static calibration trials were obtained with the participant in the anatomical position in order for the positions of the anatomical markers to be referenced in relation to the tracking clusters/markers. A static trial was conducted with the participant in the anatomical position in order for the anatomical 
positions to be referenced in relation to the tracking markers, following which those not required for dynamic data were removed.

\section{Processing}

Dynamic trials were digitized using Qualisys Track Manager in order to identify anatomical and tracking markers then exported as C3D files to Visual 3D (C-Motion, Germantown, MD, USA). All data were normalized to $100 \%$ of the stance phase. GRF and kinematic data were smoothed using cut-off frequencies of 50 and $12 \mathrm{~Hz}$ with a low-pass Butterworth 4th order zero lag filter (Sinclair, 2014). Three dimensional kinematics of the knee and ankle were calculated using an $\mathrm{XYZ}$ cardan sequence of rotations (where $\mathrm{X}=$ sagittal plane; $\mathrm{Y}=$ coronal plane and $\mathrm{Z}=$ transverse plane). Three dimensional angular kinematic measures from the knee, ankle and tibia which were extracted for statistical analysis were 1) angle at footstrike, 2) peak angle and 3) angular joint range of motion (ROM) from footstrike to peak angle. In addition the eversion/tibial internal rotation (EV/ TIR) ratio was calculated by dividing the eversion ROM by the tibial internal rotation ROM. Knee joint kinetics were computed using Newton-Euler inverse-dynamics and normalized to body mass. The peak knee adduction moment, knee adduction moment load rate (the peak increase in the adduction moment between adjacent data points) and knee adduction moment integral during the stance phase (using a trapezoidal function) were extracted.

Patellofemoral loading during the stance phase of running was quantified using a model adapted from van Eijden et al., (1986), in accordance with the protocol of Wilson et al., (2015). The hamstring force was calculated using the hip extensor moment, hamstrings and gluteus maximus cross-sectional areas (Ward et al., 2009) and by fitting a 2nd order polynomial curve to the data of Nemeth \& Ohlsen, (1985) who provided muscle moment 
arms at the hip as a function of hip flexion angle. The gastrocnemius force was calculated

202

203

204

205

206

207

208

209

210

211

212

213

214

215

216

217

218

219

220

221

222

223

firstly by quantifying the ankle plantarflexor force, which was resolved by dividing the plantarflexion moment by the Achilles tendon moment arm. The Achilles tendon moment arm was calculated by fitting a 2 nd order polynomial curve to the ankle plantarflexion angle in accordance with Self \& Paine (2001). Plantarflexion force accredited to the gastrocnemius muscles was calculated via the cross-sectional area of this muscle relative to the triceps surae (Ward et al., 2009).

The hamstring and gastrocnemius forces were multiplied by their estimated muscle moment arms to the knee joint in relation to the knee flexion angle (Spoor \& van Leeuwen, 1992), and then added together to estimate the knee flexor moment. The derived knee flexor moment was added to the net knee extensor moment quantified using inverse dynamics were then summed and subsequently divided by the quadriceps muscle moment arm (van Eijden et al., 1986), to obtain quadriceps force adjusted for co-contraction of the knee flexor musculature. Patellofemoral force was then quantified by multiplying the adjusted quadriceps force by a constant which was obtained by using the data of van Eijden et al., (1986).

Finally, patellofemoral joint stress was quantified by dividing the patellofemoral force by the patellofemoral contact area. Patellofemoral contact areas were obtained by fitting a polynomial curve to the sex specific data of Besier et al., (2005), who estimated patellofemoral contact areas as a function of the knee flexion angle using MRI. All patellofemoral forces were normalized by dividing the net values by bodyweight (BW). From the above processing, peak patellofemoral force, and peak patellofemoral stress $(\mathrm{KPa} / \mathrm{BW})$ 
were extracted. Patellofemoral instantaneous load rate (BW/s) was also extracted by obtaining the peak increase in force between adjacent data points.

227 The patellofemoral integral during the stance phase (quantified using a trapezoidal function) 228 was also calculated and the total patellofemoral force per mile $(\mathrm{BW} \cdot \mathrm{mile})$ was obtained by multiplying this parameter by the number of steps required to run a mile. The number of steps required to complete one mile was quantified using the step length $(\mathrm{m})$, which was determined by taking the difference in the horizontal position of the foot centre of mass between the right and left legs at footstrike.

Statistical analyses

Descriptive statistics of means and standard deviations were obtained for each outcome measure. Shapiro-Wilk tests were used to screen the data for normality. Differences in running distance prior to and during the intervention were examined using a paired t-test. Differences in biomechanical and knee pain parameters were examined using 2 (PRE-POST INTERVENTION) x 2 (SUBGROUP) mixed ANOVA's. Statistical significance was accepted at the $\mathrm{P} \leq 0.05$ level. Effect sizes for all significant findings were calculated using partial $\mathrm{Eta}^{2}\left(\mathrm{p} \eta^{2}\right)$. Effect sizes were contextualized using the following guidelines; small = 0.01 , medium $=0.06$ and large $=0.14$ (Cohen, 1988). All statistical actions were conducted using SPSS v24.0 (SPSS Inc, Chicago, USA). In accordance with the recommendations of 244 Crossley et al., (2017), the minimal clinically important difference (MCID) for the KOOS-PF scale was considered to be 16.4 points. For all of the other variables the MCID was

\section{Results}


249 Tables 2-5 present the knee pain, psychological wellbeing, patellofemoral loading and 250 kinematic parameters obtained before and after the 4-week intervention.

251

252 Running distance

253 No significant difference $(\mathrm{P}>0.05)$ in running distance was observed. Participants completed $25417.26 \pm 8.43 \mathrm{~km}$ of running training prior to the intervention and $17.19 \pm 6.92 \mathrm{~km}$ during the 255 intervention.

256

$257 \quad$ Knee pain

258 A significant PRE-POST INTERVENTION main effect $\left(\mathrm{P}<0.05, \mathrm{p} \eta^{2}=0.65\right)$ was observed 259 for KOOS-PF pain symptoms with participants reporting significant improvements following 260 the 4-week period. Importantly, the magnitude of the improvements exceeded the MCID in only the weak and tight sub-group (Table 2). There was no significant $(\mathrm{P}>0.05)$ main effect

\section{as a function of SUBGROUP (Table 2).}

263

264

Psychological wellbeing

265

The Coop-Wonga questionnaire showed a significant PRE-POST INTERVENTION main 266 effect of $\left(\mathrm{P}<0.05, \mathrm{p}^{2}=0.48\right)$, with participants exhibiting significant improvements following the 4-week period. Importantly, the improvements in both subgroups exceeded the MCID. There was no significant $(\mathrm{P}>0.05)$ main effect as a function of SUBGROUP (Table 
Significant PRE-POST INTERVENTION main effects were observed for both peak patellofemoral force $\left(\mathrm{P}<0.05, \mathrm{p}^{2}=0.41\right)$ and peak patellofemoral stress $\left(\mathrm{P}<0.05, \mathrm{p} \eta^{2}=0.42\right)$ with significant reductions being present following the 4-week period. Finally, a significant PRE-POST INTERVENTION main effect $\left(\mathrm{P}<0.05, \mathrm{p} \eta^{2}=0.37\right)$ was observed for patellofemoral force per mile, with significant reductions being present following the 4-week period. Importantly, in each of the aforementioned patellofemoral loading variables, the reductions exceeded the MCID in only the weak and tight sub-group (Table 3). There were no significant $(\mathrm{P}>0.05)$ main effects as a function of SUBGROUP for any of the patellofemoral loading variables (Table 3 ).

Finally, for the knee adduction moment integral, a significant PRE-POST INTERVENTION main effect $\left(\mathrm{P}<0.05, \mathrm{p \eta}^{2}=0.32\right)$ was shown, with significant increases being present following the 4-week period (Table 3). Importantly, the increase in the knee adduction moment integral exceeded the MCID in only the weak and tight sub-group (Table 3). There was no significant $(\mathrm{P}>0.05)$ main effect as a function of SUBGROUP (Table 3).

@@@TABLE3 NEARHERE@@@

\section{Joint kinematics}

For the knee sagittal angle at footstrike a significant PRE-POST INTERVENTION main effect $\left(\mathrm{P}<0.05, \mathrm{p \eta}^{2}=0.51\right)$ was shown, with the flexion angle being significantly reduced following the 4-week intervention. In addition, a significant PRE-POST INTERVENTION main effect $\left(\mathrm{P}<0.05, \mathrm{p} \eta^{2}=0.28\right)$ was shown for the magnitude of peak knee flexion, with peak flexion being significantly reduced following the 4-week period. Importantly, in each of the aforementioned joint kinematic variables, the reductions exceeded the MCID in only the 

@@@TABLE 5 NEAR HERE @@@

\section{Discussion}

This study explored the efficacy of semi-custom foot insoles in recreational runners with patellofemoral pain. The runners were categorized into previously identified subgroups (Selfe et al., 2016), which allowed the effects of the insoles to be considered by subgroup. To the authors knowledge this represents the first intervention study to explore the efficacy of insoles in recreational runners with patellofemoral pain using these targeted subgroups. Given the extremely high incidence of patellofemoral pain amongst runners, analyses of this nature may generate essential clinical information regarding conservative management of patellofemoral pain.

The first key finding from the current investigation is that both patellofemoral pain symptoms and psychological wellbeing parameters were significantly improved in both subgroups as a function of the 4-week intervention using foot insoles. This observation concurs with those of Collins et al., (2008), who showed that insoles without medial posting produced significant and clinically meaningful improvements in pain symptoms in patients with patellofemoral pain. However, it should be noted that although a large effect size was revealed, the magnitude of the improvements in pain symptoms quantified via the KOOS-PF questionnaire 
and during the intervention period, indicating that improvements in pain symptoms did not appear to be mediated through reductions in training volume. The findings indicate that insoles have the potential to provide clinically meaningful improvements in self-reported pain symptoms in runners with patellofemoral pain classified into the weak and tight subgroup according to Selfe et al., (2016). However, it should be stressed that the findings from the current study are specific to the insoles utilized in this investigation and further exploration is needed using additional insoles before substantial claims can be fully corroborated.

Of further importance to the current investigation is the observation that peak patellofemoral force/ stress and the patellofemoral force per mile were significantly attenuated in both subgroups as a function of the 4-week intervention. Contextualization of these patellofemoral loading variables showed that whilst large effect sizes were found; much like the alterations in pain symptoms the reductions only exceeded the MCID in the weak and tight group. Specifically, excessive patellofemoral joint stress is considered a key mechanism linked to the aetiology of pain symptoms in active individuals (Ho et al., 2012). Therefore, it is proposed that the improvements in pain symptoms in the weak and tight subgroup as a function of the 4-week intervention, may have been mediated as a direct consequence of the corresponding statistical reductions in patellofemoral loading.

Further to the above, it is likely that the reductions in patellofemoral loading in the weak and tight subgroup, were mediated by the corresponding reductions in knee flexion in this group which also exceeded the MCID. The alterations in knee flexion may be caused by a proprioceptive effect, facilitated by the shock attenuating properties of the insoles. This notion is supported by the observations of Sinclair et al., (2015) who found that shock absorbing insoles produced significant reductions in both knee flexion and patellofemoral 
joint loading during running. Furthermore, insoles have also been shown previously to enhance proprioception through stimulation of cutaneous mechanoreceptors (Yalla et al., 2014). The central nervous system uses ascending motor pathways that receive information from the feet to control the position of the lower extremities and coordinate movement (Christovao et al., 2013). However, because proprioception was not examined as part of this study, further confirmatory analyses are required before this can be substantiated. Nonetheless, a reduced knee flexion angle may lead to a reduction in the demands on the knee extensors during the landing phase, thus the loads imposed on the patellofemoral joint are attenuated (Thomee et al., 1999). al., (2012). As the medial tibiofemoral compartment is considerably more susceptible to injury than the lateral aspect (Wise et al., 2012) and tibiofemoral pathologies account for up to $16.8 \%$ of all knee injuries (Taunton et al., 2002) an increase in knee adduction moment is an undesirable outcome. Kean et al., (2012) also demonstrated that the integral of the knee 
adduction moment was a clinically important predictor of medial radiographic knee osteoarthritis. Therefore, whilst insoles were effective in reducing patellofemoral symptoms in the weak and tight subgroup; over time they may increase the risk of medial compartment knee osteoarthritis in this group. This is a clear and essential avenue for further longitudinal analyses to investigate the long term efficacy of insoles in runners with knee pathologies.

In conclusion, this is the first study to examine pain symptoms, psychological wellbeing and biomechanical parameters following an intervention using insoles with recreational runners subgrouped in accordance with Selfe et al. (2016). The findings showed significant improvements in self-reported pain, psychological wellbeing and patellofemoral loading as a function of the 4-week intervention. The recreational runners in the study fell into two subgroups; strong and weak and tight. Although improvements in pain were found in both groups, only the weak and tight subgroup results were associated with reductions in pain symptoms that exceeded the MCID. It is proposed that this improvement was mediated through reductions in patellofemoral stress in this subgroup. The key implication from this 
399

400

401

402

403

404

405

406

407

408

409

410

411

412

413

414

415

416

417

418

419

420

421

422

423

pain symptoms in male and female runners associated with the weak and tight subgroup. Further research including a control group and also runners from the weak and pronated group is important for advancements in the treatment of patellofemoral pain.

\section{References}

1. Almonroeder, T.G., Benson, L.C., and O'Connor, K.M. Changes in patellofemoral joint stress during running with the application of a prefabricated foot orthotic. International Journal of Sports Physical Therapy. 2015; 10: 967-975.

2. Besier, TF, Draper, C.E., Gold, G.E, Beaupre, G.S., Delp, SL. Patellofemoral joint contact area increases with knee flexion and weight-bearing. Journal of Orthopaedic Research. 2005; 23: 345-350.

3. Blond, L., Hansen, L. Patellofemoral pain syndrome in athletes: a 5.7-year retrospective follow-up study of 250 athletes. Acta Orthopædica Belgica. 1998; 64: $393-400$.

4. Bolgla, L. A., Boling, M. C. An update for the conservative management of patellofemoral pain syndrome: a systematic review of the literature from 2000 to 2010. International Journal of Sports Physical Therapy. 2011; 6: 112.

5. Cappozzo, A., Catani, F., Leardini, A., Benedeti, M.G., Della C.U. Position and orientation in space of bones during movement: Anatomical frame definition and determination. Clinical Biomechanics. 1995; 10: 171-178.

6. Christovao, T.C.L., Neto, H.P., Grecco, L.A.C., Ferreira, L.A.B., de Moura, R.C.F., de Souza, M.E., Oliveira, C.S. Effect of different insoles on postural balance: a systematic review. Journal of Physical Therapy Science. 2013; 25: 1353-1356.

7. Cohen, J. Statistical Power Analysis for the Behavioral Sciences. 1988; New York, NY: Routledge Academic. 
8. Collins, N., Crossley, K., Beller, E., Darnell, R., McPoil, T., Vicenzino, B. (2008). Foot orthoses and physiotherapy in the treatment of patellofemoral pain syndrome: randomised clinical trial. British Medical Journal. 2008; 337: 1-8.

9. Crossley, K.M., Stefanik, J.J., Selfe, J., Collins, N.J., Davis, I.S., Powers, C.M., McConnell, J., Vicenzino, B., Bazett-Jones, B.M., Esculier, J-F., Morrissey, D., Callaghan, M.J. Patellofemoral pain consensus statement from the 4th International Patellofemoral Pain Research Retreat, Manchester. Part 1: Terminology, definitions, clinical examination, natural history, patellofemoral osteoarthritis and patient-reported outcome measures. British Journal of Sports Medicine. 2016; 50: 839-843.

10. Crossley, K. M., Macri, E. M., Cowan, S. M., Collins, N. J., Roos, E. M. The patellofemoral pain and osteoarthritis subscale of the KOOS (KOOS-PF): development and validation using the COSMIN checklist. British Journal of Sports Medicine. 2017; (Epub ahead of print).

11. Decker, M.J., Torry, M.R., Wyland, D.J., Sterett, W.I., Steadman, J.R. Gender differences in lower extremity kinematics, kinetics and energy absorption during landing. Clinical biomechanics. 2003; 18: 662-669.

12. DeVita, P., Hortobagyi, T. Functional knee brace alters predicted knee muscle and joint forces in people with ACL reconstruction during walking. Journal of Applied Biomechanics. 2001; 17: 297-311.

13. Eng, J.J., Pierrynowski, M.R. Evaluation of soft foot orthotics in the treatment of patellofemoral pain syndrome. Physical Therapy. 1993; 73: 62-68.

14. Farrokhi, S., Keyak, J. H.,Powers, C. M. Individuals with patellofemoral pain exhibit greater patellofemoral joint stress: a finite element analysis study. Osteoarthritis and Cartilage. 2011; 19: 287-294. 

school female and male basketball players. Medicine \& Science in Sports \& Exercise. 2003; 35: 1745-1750.

16. Franz, J. R., Dicharry, J. A. Y., Riley, P. O., Jackson, K., Wilder, R. P., Kerrigan, D. C. (2008). The influence of arch supports on knee torques relevant to knee osteoarthritis. Medicine \& Science in Sports \& Exercise, 40, 913-917. patellofemoral joint kinetics during walking. Gait \& Posture. 2012; 36: 271-275.

18. Jensen, R., Hystad, T., Baerheim, A. Knee function and pain related to psychological variables in patients with long-term patellofemoral pain syndrome. Journal of Orthopaedics \& Sports Physical Therapy. 2005; 35: 594-600.

19. Kean, C.O., Hinman, R.S., Bowles, K.A., Cicuttini, F., Davies-Tuck, M., Bennell, K. L. Comparison of peak knee adduction moment and knee adduction moment impulse in distinguishing between severities of knee osteoarthritis. Clinical Biomechanics. 2012; 27: 520-523.

20. Lee, D.C., Pate, R.R., Lavie, C.J., Sui, X., Church, T.S. Blair, S.N. Leisure-time running reduces all-cause and cardiovascular mortality risk. Journal of the American College of Cardiology. 2014; 64: 472-481.

21. Lephart, S.M., Ferris, C.M., Riemann, B.L., Myers, J.B., Fu, F.H. Gender differences in strength and lower extremity kinematics during landing. Clinical Orthopaedics and Related Research. 2002; 401: 162-169.

22. Maclachlan, L.R., Matthews, M., Hodges, P.W., Collins, N.J., Vicenzino, B. The psychological features of patellofemoral pain: a cross-sectional study. Scandinavian Journal of Pain. 2018; 18: 261-271. 

of knee joint motion patterns between men and women in selected athletic tasks. Clinical biomechanics. 2001; 16: 438-445.

24. Nemeth, G., Ohlsen, H. In vivo moment arm lengths for hip extensor muscles at different angles of hip flexion. Journal of Biomechanics. 1985; 18: 129-140.

25. Nimon, G., Murray, D., Sandow, M., Goodfellow, J. Natural history of anterior knee pain: a 14-to 20-year follow-up of nonoperative management. Journal of Paediatric Orthopaedics. 1998; 18: 118-122.

26. Redmond, A.C., Crosbie, J., Ouvrier, R.A. Development and validation of a novel rating system for scoring standing foot posture: the Foot Posture Index. Clinical Biomechanics. 2006; 21: 89-98.

27. Robinson, R.L., Nee, R.J. Analysis of hip strength in females seeking physical therapy treatment for unilateral patellofemoral pain syndrome. Journal of Orthopaedics \& Sports Physical Therapy. 2007; 37: 232-238.

28. Sakaguchi, M., Ogawa, H., Shimizu, N., Kanehisa, H., Yanai, T., Kawakami, Y. Gender differences in hip and ankle joint kinematics on knee abduction during running. European Journal of Sport Science. 2014; 14: 302-309.

29. Self, B.P., Paine, D. Ankle biomechanics during four landing techniques. Medicine \& Science in Sports \& Exercise. 2001; 33: 1338-1344.

30. Selfe, J., Janssen, J., Callaghan, M., Witvrouw, E., Sutton, C., Richards, J., Baltzopoulos, V., Day, P. Are there three main subgroups within the patellofemoral pain population? A detailed characterisation study of 127 patients to help develop targeted intervention (TIPPs). British Journal of Sports Medicine. 2016; 50: 873-880.

31. Sinclair, J. Effects of barefoot and barefoot inspired footwear on knee and ankle loading during running. Clinical Biomechanics. 2014; 29: 395-399. 

Biomechanics. 2015; 48: 2171-2175.

33. Sinclair, J., Vincent, H., Selfe, J., Atkins, S., Taylor, P. J., Richards, J. Effects of foot orthoses on patellofemoral load in recreational runners. Foot and Ankle Online Journal. 2015; 8: 5-10.

34. Sinclair, J., Butters, B., Stainton, P. Acute effects of barefoot and minimalist footwear on medial tibiofemoral compartment loading during running: a statistical parametric mapping approach. Journal of Human Kinetics. 2018; (In press).

35. Smith, B.E., Hendrick, P., Bateman, M., Moffatt, F., Rathleff, M. S., Selfe, J., Logan, P. A mixed methods feasibility study for a loaded self-managed exercise programme for patellofemoral pain. Pilot \& Feasibility StudIES. 2017; 4: 24-28.

36. Smith, B.E., Moffatt, F., Hendrick, P., Bateman, M., Rathleff, M.S., Selfe, J., Logan, P. The experience of living with patellofemoral pain-loss, confusion and fearavoidance: a UK qualitative study. BMJ Open. 2018; 8: e018624.

37. Spoor, C.W., van Leeuwen, J.L. (1992). Knee muscle moment arms from MRI and from tendon travel. Journal of Biomechanics. 1992; 25: 201-206.

38. http://www.sportengland.org/media-centre/news/2014/september/05/sport-englandjoins-the-great-north-run-team

39. Steele, K.M., DeMers, M.S., Schwartz, M.H., Delp, S.L. Compressive tibiofemoral force during crouch gait. Gait \& Posture. 2012; 35: 556-560.

40. Sugimoto, D., Mattacola, C.G., Mullineaux, D.R., Palmer, T.G., Hewett, T.E. Comparison of isokinetic hip abduction and adduction peak torques and ratio between sexes. Clinical journal of sport medicine: official journal of the Canadian Academy of Sport Medicine. 2014; 24: 422-428. 
41. Taunton, J.E., Ryan, M.B., Clement, D.B., McKenzie, D.C., Lloyd-Smith, D.R., Zumbo, B.D. A retrospective case-control analysis of 2002 running injuries. British Journal of Sports Medicine. 2002; 36: 95-101.

42. Thomas, M. J., Wood, L., Selfe, J., Peat, G. Anterior knee pain in younger adults as a precursor to subsequent patellofemoral osteoarthritis: a systematic review. BMC Musculoskeletal Disorders. 2010; 11: 201-205.

43. Thomee, R., Augustsson, J., Karlsson, J. Patellofemoral pain syndrome: a review of current issues. Sports Medicine. 1999; 28: 245-262.

44. van Eijden, T.M., Kouwenhoven, E., Verburg, J., Weijs, W.A. A mathematical model of the patellofemoral joint. Journal of Biomechanics. 1986; 19: 219-229.

45. van Gent, R.N., Siem, D., van Middelkoop, M., van Os, A.G., Bierma-Zeinstra, S.M.A., Koes, B.W. Incidence and determinants of lower extremity running injuries in long distance runners: a systematic review. British Journal of Sports Medicine. 2007; 41: 469-480.

46. Ward, S.R., Eng, C.M., Smallwood, L.H., Lieber, R.L. Are current measurements of lower extremity muscle architecture accurate?. Clinical \& Orthopaedic Related Research. 2009; 467: 1074-1082.

47. Willson, J.D., Ratcliff, O.M., Meardon, S.A., Willy, R.W. Influence of step length and landing pattern on patellofemoral joint kinetics during running. Scandinavian Journal of Medicine \& Science in Sports. 2015; 25: 736-743.

48. Wise, B.L., Niu, J., Yang, M., Lane, N.E., Harvey, W., Felson, D. T., Lewis, C.E. Patterns of compartment involvement in tibiofemoral osteoarthritis in men and women and in whites and African Americans. Arthritis Care Research. 2012; 6: 847852. 
51.

\begin{tabular}{|c|c|c|}
\hline Overall & Strong & Weak and tight \\
\hline
\end{tabular}
adults. Clinical Biomechanics. 2014. 29: 1081-1088. disorders. Orthopedic Clinics of North America. 1992; 23: 555-566. 


\begin{tabular}{|c|c|c|c|c|c|c|}
\hline & Mean & SD & Mean & SD & Mean & SD \\
\hline $\mathbf{N}$ & \multicolumn{2}{|c|}{17} & \multicolumn{2}{|c|}{11} & \multicolumn{2}{|c|}{6} \\
\hline Age & 34.06 & 10.41 & 33.64 & 9.68 & 34.83 & 12.59 \\
\hline Body mass (kg) & 72.28 & 13.02 & 73.75 & 13.69 & 71.03 & 13.71 \\
\hline Stature (m) & 1.74 & 0.08 & 1.75 & 0.09 & 1.72 & 0.07 \\
\hline BMI $\left(\mathrm{kg} / \mathrm{m}^{2}\right)$ & 23.80 & 2.44 & 23.74 & 2.47 & 23.90 & 2.61 \\
\hline $10 \mathrm{~km}$ time (min: seconds) & $47: 24$ & $4: 16$ & $46: 26$ & 4:09 & 47:19 & $4: 10$ \\
\hline Muscle length Rectus Femoris ( ${ }^{\circ}$ ) & 135.83 & 9.60 & 134.23 & 10.29 & 138.78 & 8.17 \\
\hline Muscle Length Gastrocnemius ( ${ }^{\circ}$ ) & 66.06 & 4.19 & 65.12 & 4.52 & 67.78 & 3.14 \\
\hline Muscle strength Quadriceps (Nm/kg) & 1.38 & 0.31 & 1.55 & 0.20 & 1.06 & 0.17 \\
\hline Muscle strength hip abductors (Nm/kg) & 1.41 & 0.41 & 1.61 & 0.35 & 1.04 & 0.20 \\
\hline Patellar mobility (mm) & 11.18 & 1.91 & 11.73 & 2.00 & 10.17 & 1.33 \\
\hline Foot posture index & 3.12 & 2.03 & 3.18 & 2.14 & 3.00 & 2.00 \\
\hline
\end{tabular}


Table 2: Knee pain and psychological wellbeing parameters as a function of the foot orthoses intervention and subgroup.

\begin{tabular}{|c|c|c|c|c|c|c|c|c|c|c|}
\hline & \multicolumn{4}{|c|}{ Strong } & \multicolumn{4}{|c|}{ Weak \& Tight } & \multirow{3}{*}{\multicolumn{2}{|c|}{ MCID }} \\
\hline & \multicolumn{2}{|c|}{ Pre } & \multicolumn{2}{|c|}{ Post } & \multicolumn{2}{|c|}{ Pre } & \multicolumn{2}{|c|}{ Post } & & \\
\hline & Mean & $S D$ & Mean & $S D$ & Mean & $S D$ & Mean & $S D$ & & \\
\hline KOOS-PT & 63.84 & 9.88 & 71.49 & 10.92 & 53.03 & 16.86 & 72.73 & 7.74 & 16.40 & $\mathbf{A}$ \\
\hline COOP-WONCA & 1.91 & 0.29 & 1.55 & 0.30 & 2.08 & 0.23 & 1.83 & 0.24 & 0.16 & $\mathbf{A}$ \\
\hline
\end{tabular}

Table 3: Musculoskeletal loading and temporal parameters as a function of the foot orthoses intervention and subgroup.

\begin{tabular}{|c|c|c|c|c|c|c|c|c|c|c|}
\hline & \multirow{2}{*}{\multicolumn{4}{|c|}{ Strong }} & \multirow{2}{*}{\multicolumn{4}{|c|}{ Weak \& Tight }} & \multirow{4}{*}{\multicolumn{2}{|c|}{ MCID }} \\
\hline & & & & & & & & & & \\
\hline & \multicolumn{2}{|c|}{ Pre } & \multicolumn{2}{|c|}{ Post } & \multicolumn{2}{|c|}{ Pre } & \multicolumn{2}{|c|}{ Post } & & \\
\hline & Mean & $S D$ & Mean & $S D$ & Mean & $S D$ & Mean & $S D$ & & \\
\hline Peak Patellofemoral force (BW) & 3.40 & 0.75 & 3.08 & 0.77 & 3.68 & 1.30 & 2.85 & 1.11 & 0.54 & $\mathbf{A}$ \\
\hline Patellofemoral load rate (BW/s) & 83.59 & 18.74 & 88.63 & 22.52 & 103.13 & 30.18 & 95.45 & 35.70 & 14.83 & \\
\hline Peak patellofemoral Stress $(\mathrm{KPa} / \mathrm{BW})$ & 6.82 & 1.66 & 6.39 & 1.51 & 7.66 & 2.64 & 6.28 & 2.59 & 1.16 & $\mathbf{A}$ \\
\hline Step length $(\mathrm{m})$ & 1.31 & 0.13 & 1.33 & 0.10 & 1.36 & 0.19 & 1.38 & 0.23 & 0.09 & \\
\hline Patellofemoral force per mile $(\mathrm{BW} \cdot \mathrm{mile})$ & 183.07 & 42.25 & 155.15 & 46.84 & 189.44 & 81.54 & 138.24 & 63.03 & 32.44 & $\mathbf{A}$ \\
\hline Peak knee adduction moment $(\mathrm{Nm} / \mathrm{kg})$ & 0.89 & 0.32 & 1.02 & 0.35 & 1.02 & 0.16 & 1.11 & 0.28 & 0.18 & \\
\hline Knee adduction moment integral $(\mathrm{Nm} / \mathrm{kg} \cdot \mathrm{ms})$ & 78.57 & 35.96 & 89.97 & 38.16 & 76.67 & 23.50 & 97.73 & 28.11 & 19.69 & $\mathbf{A}$ \\
\hline Knee adduction moment load rate $(\mathrm{Nm} / \mathrm{kg} / \mathrm{s})$ & 54.50 & 16.80 & 65.85 & 25.92 & 67.85 & 19.87 & 76.73 & 24.09 & 12.61 & \\
\hline
\end{tabular}

562 Key: A = PRE-POST INTERVENTION main effect

Table 4: Knee joint kinematics parameters as a function of the foot orthoses intervention and subgroup. 


\begin{tabular}{|c|c|c|c|c|c|c|c|c|c|c|}
\hline & \multicolumn{2}{|c|}{ Pre } & \multicolumn{2}{|c|}{ Post } & \multicolumn{2}{|c|}{ Pre } & \multicolumn{2}{|c|}{ Post } & & \\
\hline & Mean & $S D$ & Mean & $S D$ & Mean & $S D$ & Mean & $S D$ & & \\
\hline \multicolumn{11}{|l|}{ Sagittal plane $(+=$ flexion $)$} \\
\hline Angle at footstrike $\left(^{\circ}\right)$ & 11.70 & 3.18 & 9.25 & 3.59 & 16.69 & 7.96 & 9.93 & 7.96 & 3.13 & $\mathbf{A}$ \\
\hline Peak flexion $\left({ }^{\circ}\right)$ & 38.86 & 4.44 & 36.62 & 4.99 & 41.54 & 10.59 & 37.64 & 9.99 & 3.78 & $\mathbf{A}$ \\
\hline Range of motion $\left(^{\circ}\right)$ & 27.15 & 3.14 & 27.37 & 3.39 & 24.85 & 7.00 & 27.71 & 8.46 & 3.04 & \\
\hline \multicolumn{11}{|l|}{ Coronal plane $(+=$ adduction $)$} \\
\hline Angle at footstrike $\left({ }^{\circ}\right)$ & -3.89 & 2.79 & -3.27 & 3.12 & -2.35 & 5.16 & -2.17 & 2.94 & 1.99 & \\
\hline Peak abduction $\left({ }^{\circ}\right)$ & -9.69 & 4.94 & -9.48 & 4.98 & -7.94 & 4.63 & -9.11 & 3.75 & 2.76 & \\
\hline Range of motion $\left({ }^{\circ}\right)$ & 5.80 & 3.43 & 6.21 & 3.49 & 5.59 & 3.58 & 6.94 & 2.13 & 1.92 & \\
\hline \multicolumn{11}{|c|}{ Transverse plane $(+=$ internal $)$} \\
\hline Angle at footstrike $\left(^{\circ}\right)$ & -5.22 & 10.95 & -1.33 & 6.94 & -4.79 & 9.29 & -0.87 & 6.62 & 5.04 & \\
\hline Peak internal rotation $\left({ }^{\circ}\right)$ & 9.71 & 7.23 & 11.68 & 5.18 & 12.47 & 6.71 & 16.26 & 4.36 & 3.80 & \\
\hline Range of motion $\left({ }^{\circ}\right)$ & 14.92 & 8.48 & 13.01 & 4.51 & 17.26 & 5.82 & 17.13 & 5.31 & 3.64 & \\
\hline
\end{tabular}

Key: A = PRE-POST INTERVENTION main effect

Table 5: Ankle and tibial kinematics as a function of the foot orthoses intervention and subgroup.

\begin{tabular}{|c|c|c|c|c|c|c|c|c|c|}
\hline & \multicolumn{4}{|c|}{ Strong } & \multicolumn{4}{|c|}{ Weak \& Tight } & \multirow{5}{*}{ MCID } \\
\hline & \multicolumn{2}{|c|}{ Pre } & \multicolumn{2}{|c|}{ Post } & \multicolumn{2}{|c|}{ Pre } & \multicolumn{2}{|c|}{ Post } & \\
\hline & Mean & $S D$ & Mean & $S D$ & Mean & $S D$ & Mean & $S D$ & \\
\hline \multirow{2}{*}{\multicolumn{9}{|c|}{$\begin{array}{c}\text { Ankle } \\
\text { Sagittal plane }(+=\text { dorsiflexi }\end{array}$}} & \\
\hline & & & & & & & & & \\
\hline Angle at footstrike $\left({ }^{\circ}\right)$ & 7.55 & 6.93 & 6.55 & 6.31 & 6.72 & 6.98 & 7.53 & 8.54 & 4.11 \\
\hline Peak dorsiflexion $\left({ }^{\circ}\right)$ & 16.86 & 4.49 & 16.80 & 4.33 & 19.49 & 5.90 & 19.57 & 6.32 & 2.94 \\
\hline Range of motion $\left({ }^{\circ}\right)$ & 11.29 & 5.57 & 11.88 & 5.31 & 13.45 & 4.17 & 12.74 & 3.72 & 2.91 \\
\hline
\end{tabular}




\begin{tabular}{|c|c|c|c|c|c|c|c|c|c|}
\hline Coronal plane $(+=$ inversion $)$ & & & & & & & & & \\
\hline Angle at footstrike $\left(^{\circ}\right)$ & -2.55 & 5.99 & -2.14 & 5.32 & -2.88 & 9.66 & 1.14 & 10.88 & 4.39 \\
\hline Peak eversion $\left(^{\circ}\right)$ & -11.79 & 6.65 & -11.21 & 7.30 & -15.55 & 10.49 & -12.49 & 9.28 & 4.71 \\
\hline Range of motion $\left(^{\circ}\right)$ & 9.24 & 2.08 & 9.06 & 3.35 & 12.67 & 4.18 & 13.62 & 4.35 & 1.95 \\
\hline \multicolumn{10}{|l|}{ Transverse plane $(+=$ external $)$} \\
\hline Angle at footstrike $\left(^{\circ}\right)$ & -13.96 & 3.93 & -13.60 & 3.37 & -16.97 & 5.86 & -13.46 & 5.16 & 3.54 \\
\hline Peak external rotation $\left(^{\circ}\right)$ & -4.84 & 4.80 & -5.03 & 5.37 & -6.38 & 4.83 & -1.12 & 6.24 & 5.13 \\
\hline Range of motion $\left({ }^{\circ}\right)$ & 9.12 & 2.59 & 8.57 & 2.74 & 10.59 & 3.42 & 12.34 & 3.20 & 1.79 \\
\hline \multicolumn{10}{|l|}{ Tibial internal rotation $(+=$ internal) } \\
\hline \multicolumn{10}{|l|}{$\begin{array}{c}\text { Transverse plane } \\
\end{array}$} \\
\hline Angle at footstrike $\left(^{\circ}\right)$ & 6.50 & 5.86 & 6.33 & 4.86 & 7.96 & 8.79 & 3.46 & 9.98 & 4.08 \\
\hline Peak tibial internal rotation $\left({ }^{\circ}\right)$ & 13.11 & 7.11 & 12.55 & 7.18 & 17.20 & 11.04 & 12.89 & 9.54 & 4.86 \\
\hline Range of motion $\left(^{\circ}\right)$ & 6.61 & 2.34 & 6.22 & 3.81 & 9.24 & 4.74 & 9.42 & 3.94 & 2.10 \\
\hline EV/TIR ratio & 1.49 & 0.43 & 1.74 & 0.59 & 1.48 & 0.28 & 1.52 & 0.34 & 0.27 \\
\hline
\end{tabular}


578

579

580

581 